\title{
What is a Critical Factor for the Re-Canalization of the External Ear Canal?
}

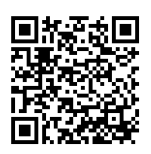

\author{
Yuji S ${ }^{1 *}$, Yoshitaka $\mathbf{W}^{2}$, Hirohisa $\mathrm{K}^{1}$, Noritaka $\mathbf{I}^{1}$ and Shinichi Asamura ${ }^{1}$ \\ ${ }^{1}$ Department of Plastic and Reconstructive Surgery, Wakayama Medical University, Japan \\ ${ }^{2}$ Department of Plastic and Reconstructive Surgery, Kindai University, Japan
}

Submission: June 29, 2020; Published: August 13, 2020

*Corresponding author: Shirakawa Y, Department of Plastic and Reconstructive Surgery, Wakayama Medical University, Japan

Abstract

Background: The incidence of obstruction of the external ear canal (EEC) is very low, and most plastic surgeons have very limited experience in corrective surgery for it. We aim to establish a standard procedure for this corrective surgery.

Methods: After a post-auricular incision is made, through which the entire EEC up to the tympanic membrane is exposed, try to excise some tissues (scar tissue, cartilage, and bone tissue) causing obstruction of the EEC. Irrespective of the size of the obstruction, the EEC floor is flattened out. This maneuver requires shaving off a bony portion of the EEC. Finally, a post-auricular cutaneous flap is placed over the defect of the EEC floor.

Results: In each case, after the removal of some bony parts, the tympanic membrane and facial nerves remained intact. All flaps successfully covered the defects and survived without any vascular problems. After 2 years of follow-up, the EEC remained patent in all cases.

Conclusion: To create an appropriate space for flap placement, it is very important to shave off a bony portion of the EEC. Technically, it is not only easier to make the floor of the EEC straight, but it also serves to prevent re-obstruction.

Keywords: External ear canal; Bony portion; Obstruction; Post-auricular cutaneous flap

\section{Introduction}

Obstruction of the external ear canal (EEC) is one of the most difficult deformities to treat, with either otologists or plastic surgeons performing correction. Mainly due to tissue contraction, the EEC is gradually is obstructed following the primary corrective surgery. Various techniques have been described to restore the patency of the EEC, with the use of skin grafts or

flaps, however, which often result in re-obstruction [1,2]. There is hardly any detailed literature regarding how the reconstruction surgery should be undertaken, based on the anatomical nature or pathogenesis of the various obstructions of the EEC. To identify a more favorable approach for the surgical correction of the obstruction, a novel approach was attempted at our institution.

\section{Surgical technique}

The sequential steps of our procedure to repair the EEC obstruction are as follows:

a) The first step: A post-auricular incision is made (Figure $1 \mathrm{~A})$, through which the entire EEC up to the tympanic membrane is exposed and excessive tissues causing the obstruction are excised.

b) The second step: Regardless of the degree of obstruction of the EEC, it is recommended that some of the bony parts of the EEC are also shaved off, taking care not to injure the tympanic membrane. With the use of a mini drill, the outer and lower floor of the bony portion must be scraped to about $5 \mathrm{~mm}$ depth, beginning at the end of the bony portion of the EEC to about $5 \mathrm{~mm}$ from the tympanic membrane. Initially the drill should be $5 \mathrm{~mm}$ of the bone is shaved off, but as progressing toward the tympanic membrane, the drill should be gradually pointed upward. In other words, the lateral horizontal view of the excised area appears to be a narrow triangle with a base of $5 \mathrm{~mm}$ in depth at the starting point (Figure 1B).

c) The third step: The operator must determine the size of the post-auricular cutaneous flap, depending upon how long and wide the ECC defect is. This flap is freely designed (Figure 1C). The elevated flap is simply transposed to the anterior side of the ear by passing it though the defect. The skin over the base of the 


\section{Global Journal of Otolaryngology}

flap is denuded. Finally, the post-auricular incision is closed with sutures. To maintain the flap attached to the underlying tissue in the deep portion of the EEC, tanponade is necessary because suturing in the deep EEC is impossible.

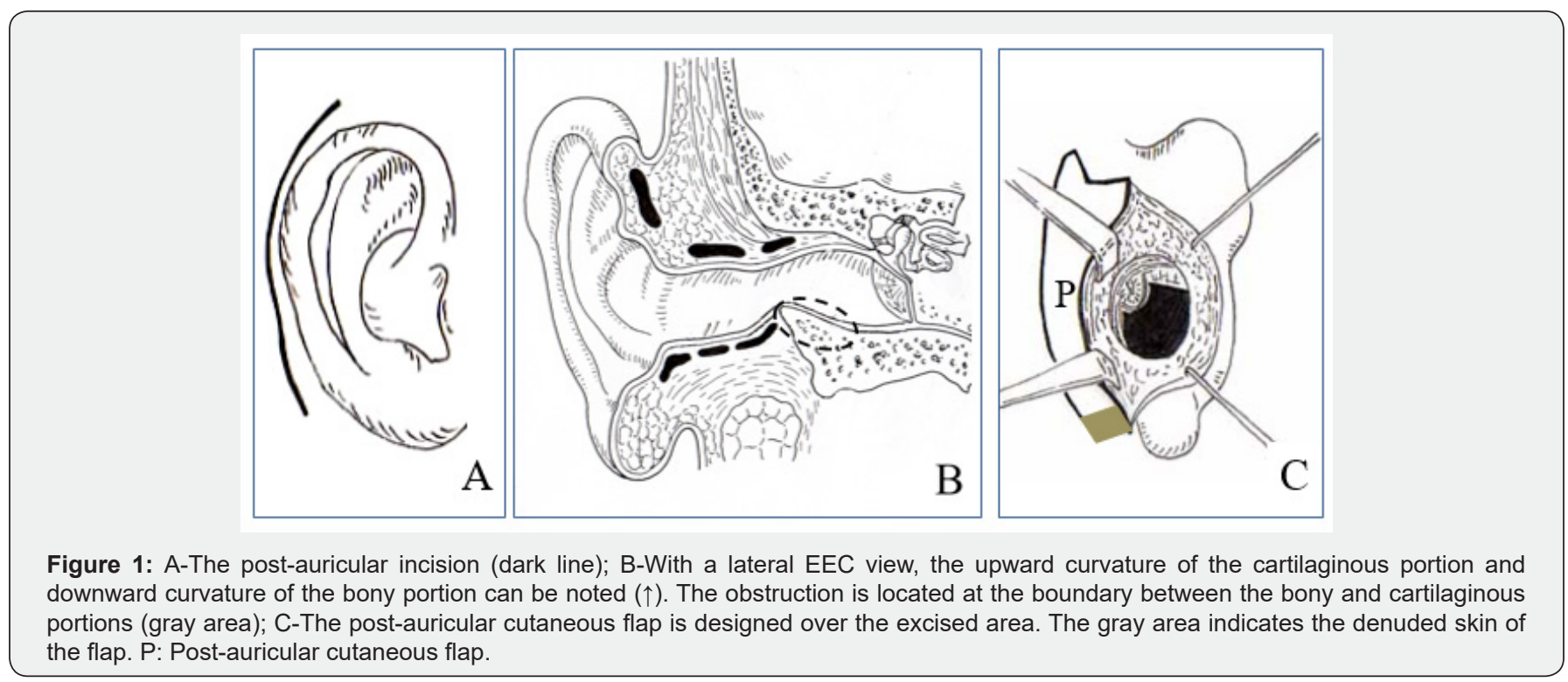

The key to successful surgery is collaboration between otologists and plastic surgeons. It is also necessary to use microscopic surgical techniques.

\section{Results}

In the 3 cases requiring the removal of some bony parts, the tympanic membrane and facial nerves remained intact. All flaps successfully covered the defects and survived without any vascular problems. After 2 years of follow-up, the EEC remained patent in all cases.

\section{Representative case presentation}

A 65-year-old man. He had suffered from a mandibular condyle fracture due to a traffic accident, which resulted in difficulty biting and fully opening the mouth. Even though he had been treated at an oral surgical clinic, he suffered from intermittent bleeding from the right ear. He subsequently developed a hearing defect, and so he visited the ear-nose-throat department of our institution. Obstruction of the EEC was diagnosed, and surgical management was recommended with the collaboration of a plastic surgeon and otologist. Examination showed an intact opening of the EEC visually, but the EEC was completely blocked at about $5 \mathrm{~mm}$ from the opening (Figure 2A). He could not carry on daily conversations because he had a left ear hearing defect, which had developed a long time before the accident.
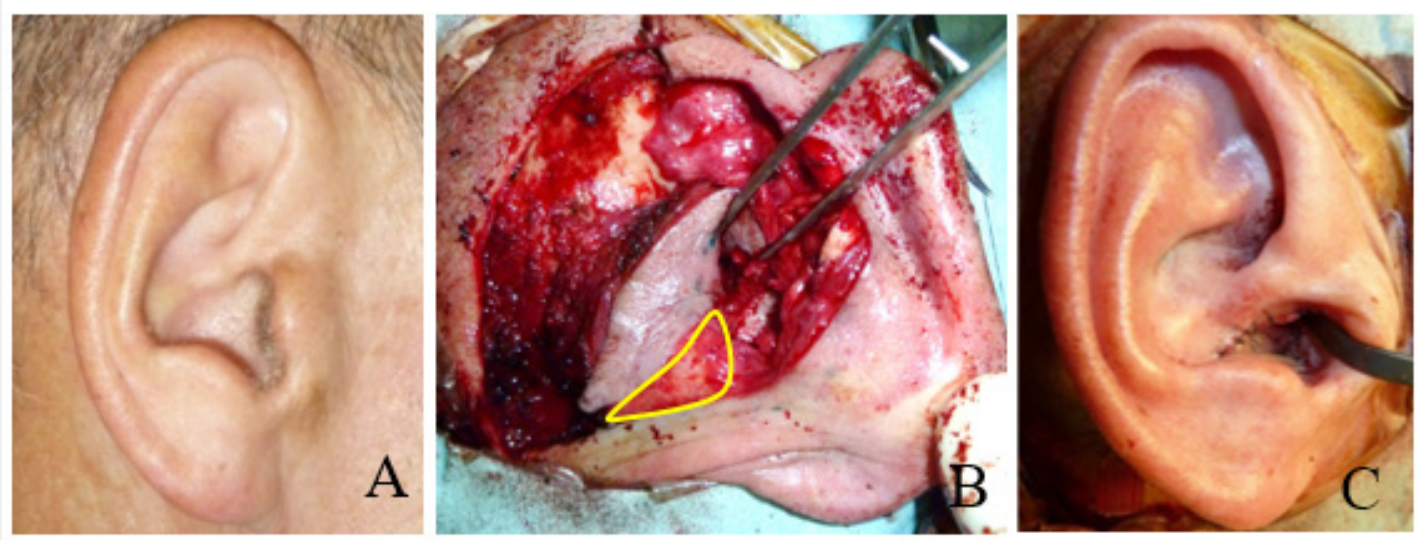

Figure 2: A-Before repair; B-The post-auricular cutaneous flap is designed over the excised area. The yellow area indicates the denuded skin of the flap. The flap is transposed to the bony portion of the EEC side by passing it through the defect. The yellow line indicates the denuded skin of the flap; C-Immediately after repair. 


\section{Global Journal of Otolaryngology}

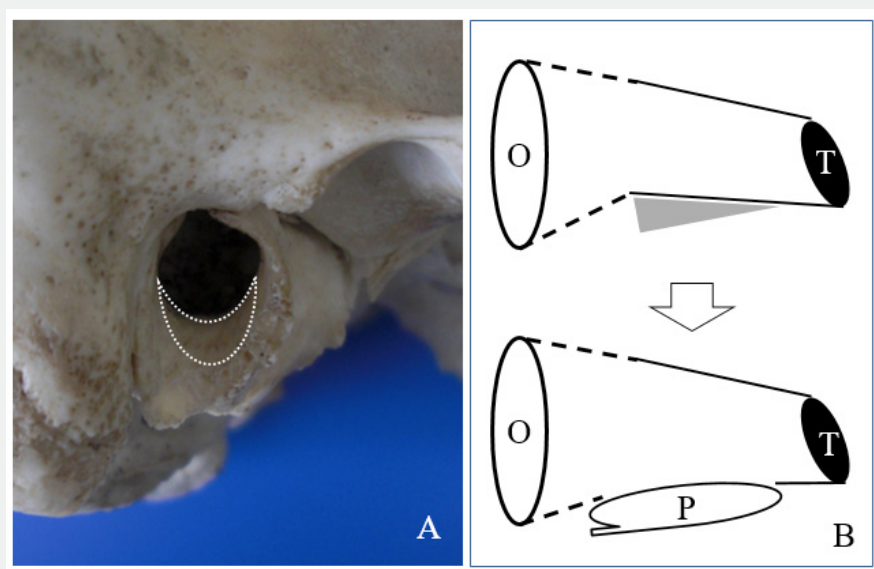

Figure 3: A-The dotted line indicates the area of the shaved bony portion of the EEC; B-A lateral horizontal view. The lateral horizontal view of the excised area shows a narrow triangle (gray) with a base of $5 \mathrm{~mm}$ in depth at the starting point. The distance from the opening $(\mathrm{O})$ of the EEC to the tympanic membrane $(\mathrm{T})$ is about $25 \mathrm{~mm}$. P: Post-auricular cutaneous flap. Above: Before repair, Below: After repair.

Through a posterior auricular incision, the cartilaginous portion of the right EEC was reached. The EEC was obstructed at the boundary between the bony and cartilaginous portions. The tympanic membrane appeared to be normal. The scar tissue, damaged cartilage, and appropriate bony portion were excised totally. The bony portion was shaved off to create a straight tunnel from the opening until the tympanic membrane. The excised area was covered with a post-auricular cutaneous flap (Figure 2B \& 2C). After the surgery, a tampon was inserted into the EEC for two weeks. His auditory function became fully restored and he could carry on ordinary conversations. The EEC remained open at approximately two years postoperatively.

\section{Discussion}

The main purpose of reconstructive surgery for EEC obstruction must be to re-establish an adequate diameter of the EEC, maintaining the auditory function. The most critical point of this surgery is shaving off the floor of the bony portion of the ECC to create a space where the flap will be placed. An obstruction of the EEC requiring reconstruction can result from several different causes, such as trauma, burns, inflammation, and malformations [1-5]. It is very important to be aware that the location and size of the obstruction can differ, depending on the pathogenesis. If it is a congenital malformation, the entire EEC is obstructed or there may be total absence of the bony or cartilaginous portion of the EEC. On the other hand, if it is acquired, usually either through trauma or burn, in general, the obstruction is located at the boundary between the bony and cartilaginous portion. Therefore, in the latter case, the bony portion is left untouched. Obstruction of the EEC frequently occurs due to extensive scar contracture.

The distance from the opening of the EEC to the tympanic membrane is about $25 \mathrm{~mm}$. The external one half of the EEC is mainly composed of cartilage, and the other half of bone. There are two fissures of Santorini, which play the role of cushions to maintain the mobility of the cartilaginous portion of the EEC where there is a channel in which nerves and vessels run [6]. These structures are vulnerable to strong pressure (Figure 3). Physiologically, the natural EEC is not a straight tunnel, but slightly torturous, with narrow and wide portions and it is almost impossible to restore the torturous EEC with a flap. Therefore, it is technically much easier to make it straight to create the new $\mathrm{EEC}$ and maintain its adequate diameter. If the bony portion is not straight, it is more likely to lead to EEC obstruction. Its secondary functions can be to maintain the patency of the EEC for removal of the accumulated ear debris and normal cosmetic appearance.

Numerous surgical techniques, such as simple stenting, dilating stent, skin grafts, which may be most common, and preauricular and/or post-auricular skin flaps, have been advocated to solve the problems mostly related to obstruction [5, 7-11]. It is extremely difficult to determine which procedure is optimal. Regardless of the location of the obstruction, a skin graft alone is not effective to appropriately reconstruct the EEC, mainly because tissue contracture is inevitable, and it is necessary to keep a stent in the EEC for a prolonged period in order to maintain its patency. Because the operative field is very deep and narrow, it is almost impossible to suture the entire skin graft to the underlying tissue in the deep portion of the EEC; therefore, the skin graft is not firmly fixed to the underlying tissue, and so it is more likely to lead to obstruction of the EEC. Based on my personal experience, a skin graft is not suitable to treat EEC obstruction.

Most of the cases reported to the present involved EEC restoration for congenital malformation. The surgical approach involved a post-auricular incision. This incision is advantageous for this type of re-canalization operation. After the incision has been made along the old scar, the size of the post-auricular cutaneous flap can be designed easily. This technique can also be applied to repair a secondary obstruction after a primary repair fails. There are reports of employing cartilage and skin 
(post-auricular chondeocutaneous flap) for re-canalization of the EEC. They reported that the additional cartilage prevents the recurrence of EEC obstruction [4,8]. The incidence of EEC obstruction is very rare, and most plastic surgeons have limited experience in corrective surgery for it. We aim to establish a standard procedure for this corrective surgery. We hope that this procedure will help other surgeons achieve favorable results on encountering such rare surgical case.

\section{Conclusion}

In order to create an appropriate space for flap placement, it is very important to shave off a bony portion of the EEC. Technically, it is not only easier to make the floor of the EEC straight, but it also serves to prevent re-obstruction.

\section{References}

1. Chang SO, Min Y, Kim CS, TY Koh (1994) Surgical management of congential aural atressia. Laryngoscope 104: 606-611.

2. Nishizaki K, Matsuda Y, Karita K (1999) Surgical management and its post-operative complications in congential aural atressia. Acta Otolaryngol Suppl 540: 42-44.

3. Macomber WB, Wang MKH, Lueders HW (1958) Reconstruction of the traumatically stenosed external auditory canal. Plast Reconstr Surg 22: $2320-2324$.

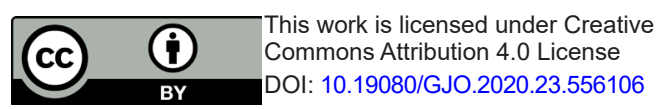

4. Furuta S, Noguchi M, Takagi N (1994) Reconstruction of stenosis of external auditory canal with a postauricular chondrocutaneous flap. Plast Reconstr Surg 94: 700-704.

5. Chang SO, Jeon S, Jeong H, Kim CS (2002) Prevention of postoperative meatal stenosis with anteriorly and inferiorly based periosteal flap in congential aural atressia surgery. Otology \& Neurotology 23: 25-28.

6. Kelly KE (1996) The external auditory canal. Anatomy and physiology. Otolaryng Clin North Am 29: 728-744.

7. Dhooge IJ, Vermeersch HF (1999) The used two pedicle skin flaps in the surgical treatment of acquired atresia of the outer ear canal. Clin Otolaryngol 24: 58-60.

8. Yotsuyanagi T, Urushidate S, Nihei Y, Yokoi K, Sawada Y, et al. (1998) Reconstruction of congenital stenosis of external auditory canal with a postauricular chondrocutaneous flap. Plast Reconstr Surg 102: 23202324.

9. Bell DR (1998) External auditory canal stenosis and atresia: Dual flap surgery. J Otolaryngol 17: 19-21.

10. Soliman T, Fatt-Hi A, Kadir MA (1980) A simplified technique for the management of acquired stenosis of external auditory canal. J Laryngol Otol 94: 549-552.

11. Benedetto GD, Pierangeli M, Zura G, Bertani A (1997) Reconstruction of external auditory canal with a laterocervical twisted flap (snail flap). Plast Reconstr Surg 99: 1745-1749.

\begin{tabular}{|l|}
\hline \multicolumn{1}{|c|}{ Your next submission with Juniper Publishers } \\
will reach you the below assets \\
- Quality Editorial service \\
- Swift Peer Review \\
- Reprints availability \\
- E-prints Service \\
- Manuscript Podcast for convenient understanding \\
- Global attainment for your research \\
- Manuscript accessibility in different formats \\
( Pdf, E-pub, Full Text, Audio) \\
- Unceasing customer service \\
Track the below URL for one-step submission \\
https://juniperpublishers.com/online-submission.php \\
\hline
\end{tabular}

